\title{
LEVANTAMENTO DE EPÍFITAS PRESENTES NA ARBORIZAÇÃO URBANA NO MUNICÍPIO DE FAROL - PARANÁ
}

\author{
Cíntia Maria Ritter ${ }^{1}$, Francielle Rocha Santos², Laianne Mayara Pezenti Crespão \\ Tábata Cristine Ardengui ${ }^{4}$, Marcelo Galeazzi Caxambu ${ }^{5}$
}

\section{RESUMO}

Epífitas são um grupo de plantas pouco estudadas, capazes de refletir o grau de preservação de um determinado ambiente, pois são sensíveis às variações ambientais decorrentes da devastação e das queimadas. As epífitas se desenvolvem sobre outras plantas, chamadas de forófitos, que servem de suporte para que as mesmas tenham acesso à iluminação necessária para garantir o seu crescimento. Este estudo teve como principal objetivo realizar o levantamento das espécies de epífitas presentes na arborização da cidade de Farol- Paraná, bem como as espécies presentes apenas nas árvores de Ligustrum lucidum, e ainda relacionar a ocorrência de epífitas com o diâmetro na altura do peito (DAP) dos indivíduos de L. lucidum. Os resultados mostraram que a maior parte das epífitas é nativa, distribuindo-se em sete famílias e dez espécies, sendo que as famílias Polypodiaceae e Bromeliaceae foram os grupos com maior número de indivíduos. Os indivíduos de Ligustrum lucidum com os maiores DAP, tenderam a apresentar maior número de espécies de epífitas, o que não ocorreu nos dois últimos intervalos avaliados (DAP: 50,1 - $60 \mathrm{~cm}$ e 60,1 - $70 \mathrm{~cm}$ ) em função de os mesmos abarcarem apenas dois indivíduos de Ligustrum lucidum cada.

Palavras-chave: Epífitas vasculares; Florística; Ligustrum lucidum.

\footnotetext{
Recebido em 19.05.2013 e aceito em 03.04.2014

1 Graduanda em Engenharia Ambiental, Universidade Tecnológica Federal do Paraná, Av. Manoel Mendes de Camargo, 630, ap. 01 - Campo Mourão-PR, cintiaritter@hotmail.com

2 Graduando em Engenharia Ambiental, Universidade Tecnológica Federal do Paraná, Av. Irmãos Pereira, 551 Ap. 2 - Campo Mourão-PR, francielleroch@hotmail.com

3 Graduanda em Engenharia Ambiental, Universidade Tecnológica Federal do Paraná, Av. Capitão Indio Bandeira, 750 ap 7 Campo Mourão- PR, laiannemayara@hotmail.com

4 Graduanda em Engenharia Ambiental, Universidade Tecnológica Federal do Paraná, Rua Prefeito Roberto Brzezinski, 1896, ap. 05 - Campo Mourão-PR, tabata.ardenghi@hotmail.com

5 Engenheiro Florestal, Universidade Tecnológica Federal do Paraná, Br 369, Km 0,5 (saída para Cascavel) bloco E - Campo Mourão-PR, mgcaxambu@yahoo.com.br
} 


\title{
SURVEY OF EPIPHYTES PRESENT ON URBAN FOREST IN FAROL'S CITY - PARANÁ
}

\begin{abstract}
Epiphytes are a group of plants little studied, able to reflect the degree of preservation of a particular environment, because are sensitive to environmental variations arising from the devastation and fires. Epiphytes grow on other plants, called phorophytes, which support so that they have access to the necessary lighting to ensure its growth.This study aimed to survey the species of epiphytes present in the urban forestry of Farol-Paraná, and the species present in tree Ligustrum lucidum, relating the occurrence with the diameter at breast height $(\mathrm{DBH})$. The results showed that most of epiphytic are native and distributed in seven families, and ten species, and the Bromeliaceae family Polypodiaceae was the groups with greater number of individuals. Ligustrum lucidum of the individuals with the highest $\mathrm{DBH}$, tended to have more species of epiphytes, which has not occurred in the last two intervals evaluated (DBH: $50,1-60 \mathrm{~cm}$ e $60,1-70 \mathrm{~cm}$ ) due to the same possess only two individuals from Ligustrum lucidum.
\end{abstract}

Keywords: Vascular epiphytes; Floristic; Ligustrum lucidum.

\section{INTRODUÇÃO}

O epifitismo é uma interação entre duas espécies, onde a epífita utiliza-se apenas do substrato fornecido pela planta portadora (forófito) como base para o seu desenvolvimento. Embora confundidas frequentemente com espécies parasitas, as epífitas são independentes do forófito na obtenção e aproveitamento de nutrientes e água (BENZING, 1990).

A ocupação das epífitas nas árvores hospedeiras está relacionada a fatores como luz, umidade e substrato (FONTOURA, 2001). Segundo Aguiar et al. (1981), elas têm um papel fundamental em estudos sobre a interferência antrópica no ambiente, são utilizadas como bioindicadoras das mudanças climáticas, poluição e danos aos ecossistemas. Elas podem refletir o grau de preservação local, uma vez que alguns grupos são menos tolerantes às variações ambientais decorrentes da devastação e das queimadas. Com base 
nessa informação, Kersten e Kuniyoshi (2009), realizaram o levantamento qualitativo de epífitas na bacia do rio Iguaçu, no Paraná, com o intuito de avaliar o grau de conservação das florestas ribeirinhas dessa região.

A importância ecológica do epifitismo nas comunidades florestais esta relacionada à manutenção da diversidade biológica e no equilíbrio interativo: as espécies epifíticas proporcionam recursos alimentares (frutos, néctar, pólen, água) e microambientes especializados para a fauna do dossel, constituída por uma infinidade de organismos voadores, arborícolas e escansoriais (WAECHTER,1992).

Para Dettke et al. (2008), os estudos sobre epífitas vêm crescendo nas últimas décadas, os quais enfocam além da composição florística, diversos aspectos ecológicos como, distribuição altitudinal, síndromes de polinização e dispersão, entre outros.

No Estado do Paraná, pode-se destacar estudos como o de Blum et al. (2011) o qual analisou a composição florística e a distribuição altitudinal de epífitas na Serra da Prata; o de Morretes feito por Borgo e Silva (2003), que verificaram os epífitos vasculares em fragmentos de Floresta Ombrófila Mista em Curitiba; o de Dettke et al. (2008), que realizou o levantamento e a análise da distribuição de epífitas no Parque do Ingá, em Maringá; e ainda, o de Geraldino et al. (2010), que apresentou a composição florística e estrutural da comunidade de epífitas em uma área de ecótono em Campo Mourão.

Com relação ao levantamento das espécies de epífitas ocorrentes na arborização urbana pode-se citar Fabricante et al. (2006), o qual apresenta os epífitos ocorrentes em árvores urbanas do município de Piratininga, São Paulo. No Paraná, até o momento, não se tem nenhum estudo nesse aspecto.

Tendo em vista a escassez de estudos sobre a ocorrência de epífitas na arborização urbana do Paraná, este trabalho teve como objetivo caracterizar a composição florística e estrutural das epífitas presentes na arborização urbana da cidade de Farol- Paraná, e relacionar o DAP de Ligustrum lucidum W. T. Aiton, espécie arbórea predominante na arborização do município estudado, com a presença de epífitas, contribuindo assim para um maior conhecimento deste grupo de plantas.

\section{MATERIAIS E MÉTODOS}

O estudo foi realizado em árvores da malha urbana da cidade de Farol (Figura 1), mesorregião centro ocidental paranaense (IPARDES, 2012). O município pertence ao bioma 
Mata Atlântica e ao Terceiro Planalto Paranaense ou Planalto de Guarapuava. Possui uma área de 289 km² e altitude de 630 metros acima do nível do mar (IBGE, 2010).

De acordo com Instituto de Terras, Cartografia e Geociências- ITCG (2009), a formação fitogeográfica predominante nessa região é um ecótono entre a Floresta Estacional Semidecidual e a Floresta Ombrófila Mista Montana.

O clima da região é o Cfa de acordo com a classificação de Köeppen (subtropical úmido mesotérmico), com temperaturas entre $18{ }^{\circ} \mathrm{C}$ e $22^{\circ} \mathrm{C}$, com verões quentes, geadas pouco freqüentes, sem estação seca definida, e maior concentração de chuvas no verão (IAPAR, 2000).

Os solos encontrados nessa região são Latossolo (solo profundo, bem drenado, e com elevado potencial de utilização) e Argissolo (solo profundo, bem drenado, apresenta um acúmulo de argila no horizonte $\mathrm{B}$, e muito sujeito à erosão, pois o horizonte $\mathrm{A}$ é composto por grande quantidade de areia) (ITCG, 2008; EMBRAPA FLORESTAS, 2012).

Figura 1. Localização do município de Farol no Estado do Paraná e na mesorregião Centro Ocidental Paranaense

Figure 1. Map locator of Farol city in the state of Paraná and mesoregion center-west

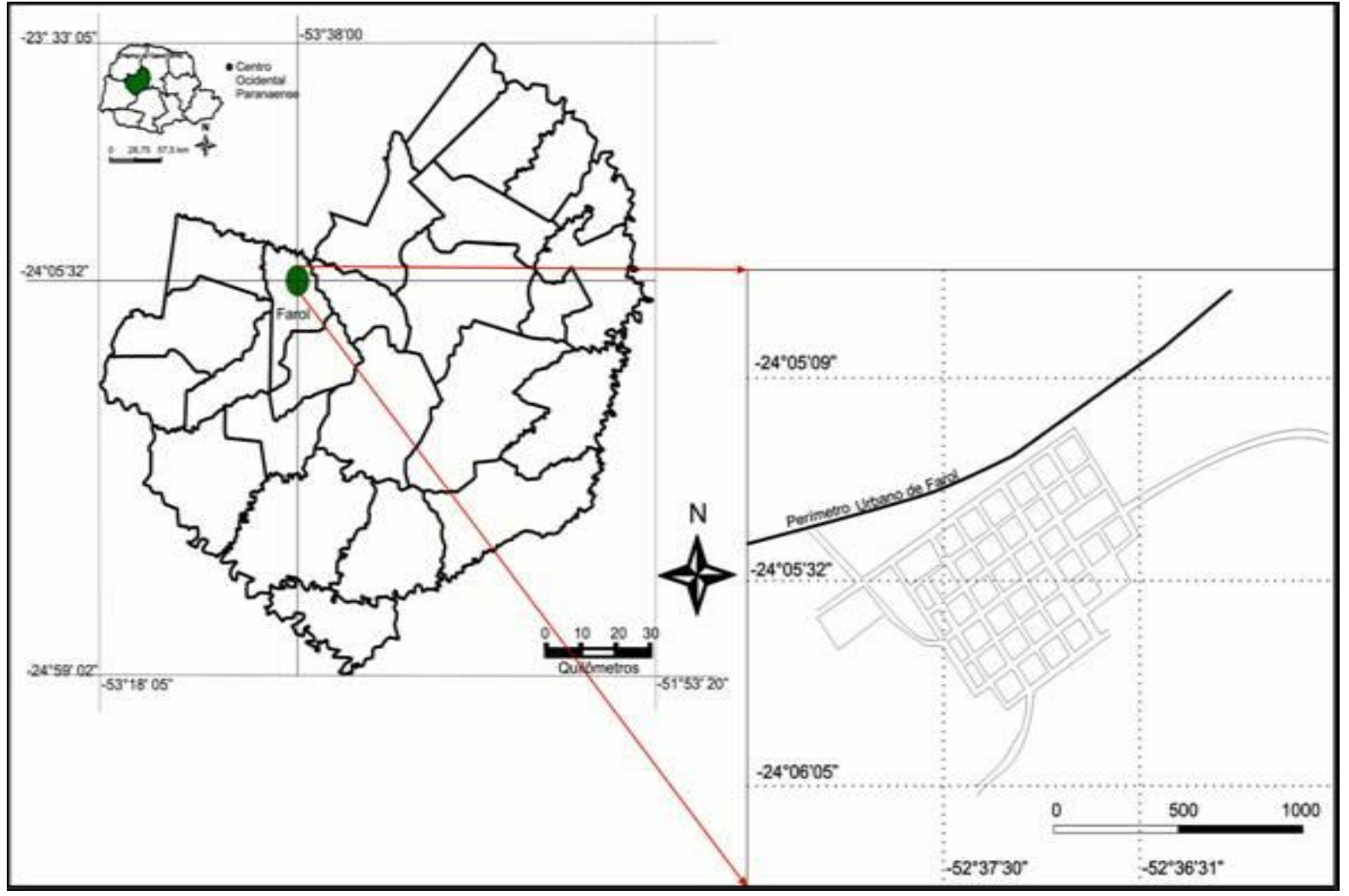

Fonte: Adaptado de Menezes (2008). 
O levantamento foi realizado entre os meses de abril e maio de 2013 , foram contabilizados todos os exemplares de epífitas, presentes na arborização urbana do município.

O material botânico foi coletado com o auxílio de tesoura de poda alta (podão), e tesoura de poda, seguindo as técnicas usuais em levantamentos florísticos conforme proposto por Fidalgo e Bononi (1989). Em seguida, o material foi levado para as dependências do Herbário da Universidade Tecnológica Federal do Paraná campus Campo Mourão (HCF) onde, foi então conduzida a identificação das epífitas com base na comparação à coleção do HCF.

As epífitas foram classificadas como nativa do Brasil ou exótica, segundo a Flora do Brasil (2013) e IPNI (2013). E ainda, de acordo com a classificação proposta por Benzing (1990), baseando-se no tempo de permanência destas sobre os forófitos - Holoepífitas verdadeiras: Plantas que em nenhum momento de sua vida matêm contato com o solo; Holoepífitas acidentais: plantas que, embora não possuam nenhuma adaptação para o hábito epifítico, podem, ocasionalmente, crescer sobre outros vegetais; Epífitas cultivadas: Plantas que foram propositalmente colocadas em alguma árvore pelo homem, geralmente devido às florações ou mesmo folhagens exuberantes.

Foram coletadas todas as espécies de epífitas encontradas na arborização urbana do município, independentemente de qual espécie arbórea lhes serviam de forófito. Através desse levantamento, elaborou-se a lista de epífitas encontradas na arborização urbana de Farol.

Após realizar um levantamento prévio das espécies arbóreas encontradas no município de Farol, observou-se que existia baixa variabilidade de espécies arbóreas na arborização urbana de Farol, sendo a espécie Ligustrum lucidum W. T. Aiton a espécie predominante na arborização, com 91 indivíduos, logo, utilizou-se da mesma para fazer a relação entre DAP e presença de epífitas. O cálculo do Diâmetro à Altura do Peito (DAP) foi obtido diretamente com fita métrica.

\section{RESULTADOS E DISCUSSÃO}

$\mathrm{Na}$ arborização urbana do município de Farol foram identificadas 10 espécies de epífitas as quais são distribuídas em sete famílias distintas. Esses dados corroboram com os encontrados por Fabricante et al (2006) na arborização urbana de Piratininga em São Paulo, o qual, atribui o reduzido número de espécies encontradas, se comparadas a outros 
estudos, ao fato de se tratar de uma área urbana, sendo esta pouco similar aos habitats naturais das espécies.

Tabela 1. Lista de epífitas encontradas na arborização urbana de Farol- PR

Table 1. List of epiphytes found in the urban forestry of Farol- PR

\begin{tabular}{c|c|c|c}
\hline \multirow{2}{*}{ Família } & Espécie & $\begin{array}{c}\text { Verdadeira/ } \\
\text { Acidental / Cultivada }\end{array}$ & $\begin{array}{c}\text { Nativa/ } \\
\text { Exótica }\end{array}$ \\
\hline Araceae & Syngonium podophyllum Schott & Verdadeira & Exótica \\
\hline Bignoniaceae & Handroanthus heptaphyllus Mattos & Acidental & Nativa \\
\hline Bromeliaceae & Tillandsia recurvata (L.) L. & Verdadeira & Nativa \\
\hline & Tillandsia tricholepsis (L.) & Verdadeira & Nativa \\
\hline Cactaceae & Epiphyllum phyllanthus (L.) Haworth & Verdadeira & Nativa \\
\hline Myrtaceae & Eugenia uniflora L. & Acidental & Nativa \\
\hline Orchidaceae & Dendrobium nobile Lindl & Cultivada & Exótica \\
\hline Polypodiaceae & Microgramma squamulosa (Kaulf.) de la Sota & Verdadeira & Nativa \\
\hline & Pleopeltis pleopeltifolia (Raddi) Alston & Verdadeira & Nativa \\
\hline & Pleopeltis squalida (Vell.) de la Sota & Verdadeira & Nativa \\
\hline
\end{tabular}

As famílias Polypodiaceae e Bromeliaceae, apresentaram o maior número de espécies, representando $30 \%$ e $20 \%$ respectivamente, dos epífitos amostrados. Tal resultado mostra a mesma tendência já revelada em outras pesquisas realizadas no Paraná (DETTKE et al., 2008; BLUM et al.; 2011; BORGO; SILVA, 2003; GERALDINO et al., 2010).

Das espécies de epífitas encontradas, $80 \%$ são espécies nativas, $20 \%$ espécies exóticas. Há um predomínio de espécies de epífitas verdadeiras $(70 \%)$, sendo as demais, duas espécies de epífitas acidentais e apenas uma espécie de epífita cultivada.

Tabela 2. Lista de epífitas encontradas em Ligustrum lucidum W. T. Aiton na arborização urbana de Farol- PR

Table 2. List of epiphytes found in Ligustrum lucidum W. T. Aiton in the urban forest of Farol- PR

\begin{tabular}{c|c}
\hline Família & Espécie \\
\hline Araceae & Syngonium podophyllum Schott \\
\hline Bignoniaceae & Handroanthus heptaphyllus Mattos \\
\hline Bromeliaceae & Tillandsia recurvata (L.) L. \\
\hline Cactaceae & Epiphyllum phyllanthus (L.) Haworth \\
\hline Myrtaceae & Eugenia uniflora L. \\
\hline
\end{tabular}




\begin{tabular}{c|c}
\hline Família & Espécie \\
\hline Orchidaceae & Dendrobium nobile Lindl \\
\hline Polypodiaceae & Microgramma aquamulosa (Kaulf.) de La Sota \\
\hline & Pleopeltis pleopeltifolia (Raddi) Alston \\
\hline & Pleopeltis squalida (Vell.) de la Sota \\
\hline
\end{tabular}

Foram encontrados 91 exemplares de Ligustrum lucidum W. T. Aiton na arborização urbana de Farol, sendo que em apenas 24 destes (26\%) há presença de epífitas.

Nove espécies de epífitas estão presentes no Ligustrum lucidum, estas, distribuídas em sete famílias. Houve o predomínio da família Polypodiaceae, com três espécies $(33,33 \%)$, as outras seis famílias apresentaram apenas uma espécie de epífita.

Dos 24 exemplares de L. lucidum que apresentaram epífitas, em 18 (75\%) Pleopeltis pleopeltifolia esteve presente, sendo a epífita que predominante em L. lucidum na arborização urbana de Farol, visto que as outras espécies tiveram pouca incidência.

Pode-se observar que das dez espécies de epífitas encontradas na arborização de Farol, 90\% pode ser encontrada utilizando L. lucidum como forófito. A única espécie que estava presente na arborização, mas não foi encontrada em neste forófito foi Tillandsia tricholepsis. A mesma relação pode ser feita para as famílias, uma vez que das sete encontradas no município, todas se fazem presentes em indivíduos de L. lucidum espalhados pela arborização urbana de Farol.

Tabela 3. Relação entre diâmetro da altura do peito (DAP) do Ligustrum lucidum W. T. Aiton e a presença de epífitas

Table 3. Relationship between Diameter at breast height (DBH) of Ligustrum lucidum W. T. Aiton and epiphytes

\begin{tabular}{|c|c|}
\hline DAP (cm) & Espécie \\
\hline $1-10$ & Pleopeltis pleopeltifolia (Raddi) Alston \\
\hline $10,1-20$ & Pleopeltis pleopeltifolia (Raddi) Alston \\
\hline \multirow[t]{2}{*}{$20,1-30$} & Pleopeltis pleopeltifolia (Raddi) Alston \\
\hline & Tillandsia recurvata (L.) L. \\
\hline \multirow[t]{3}{*}{$30,1-40$} & Microgramma aquamulosa (Kaulf.) de la Sota \\
\hline & Pleopeltis pleopeltifolia (Raddi) Alston \\
\hline & Pleopeltis squalida (Vell.) de la Sota \\
\hline \multirow[t]{5}{*}{$40,1-50$} & Pleopeltis pleopeltifolia (Raddi) Alston \\
\hline & Tillandsia recurvata (L.) L. \\
\hline & Handroanthus heptaphyllus Mattos \\
\hline & Eugenia uniflora $\mathrm{L}$. \\
\hline & Pleopeltis squalida (Vell.) de la Sota \\
\hline
\end{tabular}




\begin{tabular}{c|c}
\hline DAP $(\mathbf{c m})$ & Espécie (Species) \\
\hline & Epiphyllum phyllanthus (L.) Haworth \\
\hline $50,1-60$ & Dendrobium nobile Lindl. \\
\hline & Microgramma aquamulosa (Kaulf.) de la Sota \\
\hline $60,1-70$ & Pleopeltis pleopeltifolia (Raddi) Alston \\
\hline & Microgramma aquamulosa (Kaulf.) de la Sota \\
\hline & Pleopeltis pleopeltifolia (Raddi) Alston \\
\hline
\end{tabular}

Ao relacionarmos o DAP, com a presença de epífitas, observou-se que $P$. pleopeltifolia, é a espécie de epífita que começa o processo de colonização em cima de $L$. lucidum.

Pode-se verificar que os indivíduos de L. lucidum com DAP inferior a $20 \mathrm{~cm}$ apresentaram apenas uma espécie de epífita, sendo esta $P$. pleopeltifolia. A partir de $20 \mathrm{~cm}$ de DAP, outras epífitas passaram a colonizar o forófito.

Nota-se que a faixa de DAP 40,1-50 cm, foi a que mais apresentou epífitas, sendo no total sete espécies diferentes. As faixas 30,1-40 cm e 60,1-70 cm apresentaram três espécies de epífitas cada, sendo que duas destas ocorrem em ambas as faixas.

Foi registrada a presença de Dendrobium nobile Lindl, Handroanthus heptaphyllus Mattos, Eugenia uniflora L. e Epiphyllum phyllanthus (L.) Haworth apenas na faixa de DAP de 40,1-50 cm. Já Syngonium podophyllum Schott apareceu apenas uma vez, apenas em DAP superior a $60,1 \mathrm{~cm}$.

Dias (2009), observando ambientes com árvores de grande porte, postula que estas estão a mais tempo suscetíveis ao estabelecimento de propágulos de espécies epifíticas. Assim, corrobora-se o fato que as árvores que possuem maiores DAP's tendem a ter maior abundância e riqueza de epífitas.

\section{CONCLUSÕES}

Com base no levantamento realizado das epífitas ocorrentes na arborização urbana de Farol, Paraná, foram encontradas 10 espécies, distribuídas em sete famílias, onde Polypodiaceae é a mais rica em número de espécies de epífitas.

Das espécies de epífitas encontradas, $80 \%$ são espécies nativas e há um predomínio de epífitas verdadeiras. 
Foi constatado que a espécie Pleopeltis pleopeltifolia além de ser a epífita predominante em Ligustrum lucidum é a espécie que inicia o processo de colonização sobre o mesmo.

Por fim, a faixa de DAP entre $40,1-50 \mathrm{~cm}$, foi a que apresentou maior quantidade de epífitas, sendo no total sete espécies diferentes. Isto parece estar relacionado com o fato de que a árvore teve mais tempo para se desenvolver e criar um microclima adequado para o estabelecimento de epífitas.

Nos intervalos $50,1-60 \mathrm{~cm}$ e $60,1-70 \mathrm{~cm}$, foram encontradas apenas duas e três espécies de epífitas respectivamente, o que está relacionado ao pequeno número de indivíduos de L. lucidum dentro destes intervalos (apenas dois para cada uma das faixas).

\section{REFERÊNCIAS}

AGUIAR, L. W.; CITADINE -ZANETTE, V.; MARTAU ,L.; BACKES, A. Composição florística de epífitos vasculares numa área localizada no município de Montenegro e Triunfo, Rio Grande do Sul, Brasil. Iheringia, Série Botânica. v. n. 28, p. 55-93, 1981.

BENZING, D. H. Vascular epiphytes. Cambridge University Press, Cambridge, p.354, 1990.

BLUM, C. T.; RODERJAN, C. V.; GALVÃO, F. Composição florística e distribuição altitudinal de epífitas vasculares da Floresta Ombrófila Densa na Serra da Prata, Morretes, Paraná, Brasil. Biota Neotropica. v. 11, n. 4, p. 141-159, 2011.

BORGO, M.; SILVA, S. M.; Epífitos vasculares em fragmentos de Floresta Ombrófila Mista, Curitiba, Paraná, Brasil. Revista Brasileira de Botânica, São Paulo, v. 26, n. 3, p. 391-401, 2003.

DETTKE, G. A.; ORFRINI, A. C.; MILANEZE-GUTIERRE, M. A. Composição florística e distribuição de epífitas vasculares em um remanescente alterado de Floresta Estacional Semidecidual no Paraná, Brasil. Rodriguésia, Rio de Janeiro, v. 59, n. 4, p. 859-872, 2008.

DIAS, A. dos S. Ecologia de epífitas vasculares em uma área de mata atlântica do Parque Nacional da Serra dos Órgãos, Teresópolis, RJ. 2009. 61f. Dissertação (Mestrado em ciências) - Programa de pós-graduação em ciências ambientais e florestais da Universidade Federal Rural do Rio de Janeiro, Teresópolis, RJ, 2009.

EMBRAPA FLORESTAS, 2012. Mapa simplificado de solos do Estado do Paraná. Disponível em: < http://www.escola.agrarias.ufpr.br/arquivospdf/mapa_solos_pr.pdf> Acesso em: 14 mai. 2013. 
FABRICANTE, J. R.; ANDRADE, L. A. de; MARQUES, F. J. Componente epifítico vascular ocorrente em árvores urbanas. Cerne, Lavras, v. 12, n. 4, p. 399-405, 2006.

FIDALGO, O.; BONONI, V. L. R. Técnicas de coleta, preservação e herborização de material botânico. São Paulo: Instituto de Botânica, p. 62, 1989.

FLORA DO BRASIL. Lista de Espécies da Flora do Brasil. Disponível em: < http://floradobrasil.jbrj.gov.br/> Acesso em: 13 mai. 2013

FONTOURA, T. Bromeliaceae e outras epífitas - estratificação e recursos disponíveis para animais na Reserva Ecológica Estadual de Jacarepiá, Rio de Janeiro. Revista Brasileira de Bromélia, Rio de Janeiro, v. 6, p. 33-39, 2001.

GERALDINO, H. C. L.; CAXAMBÚ, M. G.; SOUZA, D. C. Composição florística e estrutura da comunidade de epífitas vasculares em uma área de ecótono em Campo Mourão, PR, Brasil. Acta Botânica Brasílica, São Paulo, v. 24, n. 2, p. 469-482, 2010.

IAPAR - Instituto Agronômico do Paraná, 2000. Cartas Climáticas do Paraná. Disponível em: http://www.iapar.br/modules/conteudo/conteudo.php?conteudo=677> Acesso em: 23 mar. 2013.

IBGE - Instituto Brasileiro de Geografia e Estatística, 2010. Cidades. Disponível em: < http://www.ibge.gov.br/cidadesat/painel/painel.php?codmun=410755\#> Acesso em: 20 mar. 2013.

IPARDES - Instituto Paranaense de Desenvolvimento Econômico e Social. 2012. Relação dos municípios segundo as regiões geográficas do Paraná- 2012. Disponível em: < http://www.ipardes.gov.br/pdf/mapas/base_fisica/relacao_mun_regiao_geografica_parana.pd f> Acesso em: 14 mai. 2013.

IPNI - The International Plant Names Index. 2013. Disponível em: < http://www.ipni.org/> Acesso em: 13 mai. 2013.

ITCG - Instituto de Terras, Cartografia e Geociências, 2008. Solos- Estado do Paraná. Disponível em: <http://www.itcg.pr.gov.br/modules/conteudo/conteudo.php?conteudo=47> Acesso em: 12 mai. 2013.

ITCG - Instituto de Terras, Cartografia e Geociências, 2009. Formações Fitogeográficas Estado do Paraná. Disponível em: <http://www.itcg.pr.gov.br/arquivos/File/Produtos DGEO/Mapas_ITCG/PDF/Mapa_Fitogeografico_A3.pdf> Acesso em: 21 mar. 2013. 
KERSTEN, R. de A.; KUNIYOSHI, Y. S. Conservação das Florestas na Bacia do Alto Iguaçu, Paraná- Avaliação da comunidade de epífitas vasculares em diferentes estágios serais. Floresta, Curitiba, PR, v. 39, n. 1, p. 51-66, 2009.

MENEZES, H.R, Mapa Político do Paraná, 2008.

WAECHTER,J.L. O epifitismo vascular na Planície Costeira do Rio Grande do Sul. 1992. 163f. Tese (Doutorado em Ecologia e Recursos Naturais) - Centro de Ciências Biológicas e da Saúde, Universidade Federal de São Carlos, São Carlos, 1992. 